\title{
Learning Leadership: A Qualitative Study on the Differences of Student Learning in Online versus Traditional Courses in a Leadership Studies Program
}

\author{
Amber Manning-Ouellette, Ph.D. \\ Lecturer of Leadership Studies \\ Iowa State University \\ Katie M. Black \\ Research Assistant \\ Iowa State University
}

\begin{abstract}
As online education offerings are extended to more students, organizations are increasingly interested in the effectiveness of online learning compared to a traditional classroom. The need for research on the learning outcomes of students is imperative. The purpose of this study is to compare student learning in a traditional classroom with the equivalent online course. This research explores the research question: What is the difference between student learning in a leadership studies course through online versus traditional delivery methods? This study utilizes a directed content analysis to investigate student assignments using Kolb’s Experiential Learning Model as a foundational theory. Previous research reveals a contradiction on student outlook on the instructor and format of the class, as well as understanding the effectiveness of each method of delivery. Findings in this study indicate that online students may engage more often in deeper learning on assignments than those in the traditional classroom environment.
\end{abstract}

\section{Introduction}

A traditional classroom is becoming less and less relevant in this day in age. Technology is slowly taking over the undergraduate student experience including daily tasks, news outlets, and the learning environment. It is imperative that higher education institutions continue to compete in evolving educational environments. Through the help of technology, online courses have become readily available to students. The demand for these courses has risen, however online courses are not free from criticism. It is important for educators to research the benefits and effectiveness of online learning compared to the traditional classroom. By researching the benefits and effectiveness of online courses, educators can examine what students might be missing in their learning process, why they are unable to transform their educational experiences, or why they are not engaging with material. Furthermore, examining the student learning process of online and traditional classrooms helps to understand how and what to incorporate into course structure for students. 
Research Purpose and Questions. In reviewing online learning literature, very few studies examined a simultaneous course in two formats. This study employs a qualitative stance on the learning process on course assignments in both the online and traditional classroom-learning environment. In particular, we investigate one leadership studies course instructed by the same faculty member in two delivery methods - online and traditional. We posit the importance of instituting a qualitative methodology in this study is to examine learning through a content analysis to better understand learning style on course assignments. Further, previous research studies examine differences in surface and deeper learning, but often do not employ the Kolb Experiential Learning Theory (ELT). Our work fills the gap in previous literature and also utilizes the Kolb's ELT as a framework for understanding student learning through assignments. This study centers the research question:

1. What is the difference between student learning in a leadership studies course through online versus traditional delivery methods?

\section{Literature Review}

Over the past 15 years, literature continues to provide conflicting answers about learning in online and traditional classroom formats. Moreover, one of the largest studies to date by Russell (1999) indicates that there are no significant differences in online and traditional classroom learning. While the Russell (1999) study is large-scale, several researchers are critical of this research. Examining the effectiveness of an online course is important because college tuition is steadily increasing, college debt is at its highest and a secondary degree is the most sought after form of advancing one's life. Online courses are attractive because they are cost effective, convenient for college students, and often times fit better into an individual's schedule. The topic of online course effectiveness is central to many university administrative conversations because of revenue and research studies prove to be optimistic about online courses (Hill, 2016; Lapovsky, 2015). However, research studies also continue to contradict in areas surrounding engagement, instructional design, retention of information, and expose some of the negative influence on student learning. Finally, research on learning technologies needs to remain current so the importance of timely data and research is a significant concern for faculty and staff. In the preceding section, we review the foundational literature examining previous research on online and traditional student learning.

Instructional Course Design. Researchers and faculty have much to learn from course design and delivery. The amount of literature on course design is extensive and investigates the influences on students' success in courses. In particular, online courses can provide diverse access which assists in the flexibility of student learning at any time or place, yet it is incredibly important to use intentional design and curriculum to support deeper learning (Ally, 2014; Cole, 2000; Lehamn, \& Conceicao, 2014). Faculty must pay particular attention to the design of a course and support learning and engagement (Ally, 2014). Specifically, Nash (2005) and Picciano (2002) discuss a crucial component to course design is social presence. Piccaino (2002) cites, "the success of many online courses is dependent upon the nature of student to student and student to faculty interaction" (p. 33). Course design should provide multiple outlets for social presence and interactions that are intentional. 
Intentionality and clarity of design is essential in both traditional and online courses. More specifically, there are several components to intentional and clear courses identified by several researchers: a) variety of presentation, b) frequent and clear feedback, c) follow up, d) consistent layout, e) concise navigation, and f) support (Janicki \& Liegle, 2001; Mazzolini \& Maddison, 2007; Nandi, Hamilton, \& Harland, 2012; Swan, 2001). The design structure of a course is complex, but drives how persistent and successful students are in the course. More specifically, Nandi, Hamilton, \& Harland (2012) posit, "that rather than designing a fully student-centered or instructor-centered discussion, a combination of both approaches can be advantageous" (p. 27). Their work highlights the design approach that is most beneficial to student learning and how student persistence is centered in devoting a mixed-method pedagogical approach.

Finally, course design should include specific learning objectives in which the instructor assesses mastery of content. In higher education, learning objectives are broadly referred to as anything that has an educational purpose (McGreal, 2004; Nash, 2005). Designing a concise and effective course includes defining clear objectives and building around those (Janicki \& Leigle, 2001; Nash, 2005; Picciano, 2002). Students should also understand and identify those objectives when completing work within modules or lessons for increased learning (Ally, 2014; Lehamn, \& Conceicao, 2014). Instructors should consider an overall learning objective approach when designing courses for transparency and optimal student learning.

Online Classroom. Research studies indicate that regardless of the background of demographics of students, there is an increase in student-learning outcomes for online learners, compared to traditional learners (Ally, 2014; Nguyen, 2015; Schutte, 1997). Findings expose that students were often times more satisfied with online learning versus traditional classroom environments (Navarro \& Shoemaker, 2000; Nguyen, 2015). Satisfaction in online courses is connected to instructor presence and interactions contribute to overall higher scores within an online environment (Richardson \& Swan, 2003). Moreover, researchers also note, that an "advantage of asynchronous learning is it allows students to reflect upon the materials and their responses before responding, unlike traditional classrooms (Richardson \& Swan, 2003, p. 69). The authors indicate the ability to process material and make sense of the concepts before responding to the question or prompts in the online format.

There are few studies that examine the differences in learning through the same course in two delivery methods. One study conducted by Schutte (1997) investigated 33 students in a social statistics course. Students in the study were split into two groups, a traditional classroom and an online version. Results demonstrated the online class scored an average of $20 \%$ higher than the traditional classroom on examinations. Overall, the online course had a higher understanding of the material at the end of the semester (Schutte, 1997). Further, researchers have found that in the online environment, students learn more by doing rather than watching (Koedinger, Kim, Zhuxin Jia, McLaughlin, \& Bier, 2015). More specifically, research indicated that short educational videos did not engage and increase mastery of content. Actively engaging students in the online environment may have a significant influence on student learning (Koedinger, et al., 2015). 
To the contrary, studies also indicate negative feelings toward online education. A study on a microeconomics course completed by Brown and Liedholm (2002) resulted in students performing worse on tests than students in the traditional classroom even with higher overall grade point averages and ACT scores. Several criticisms of online learning include the lack of stability in the learning environment, partly due to continuously changing technology (Brandt, 1996). Other studies indicate that online instruction threatens to commercialize education, continues to isolate students and faculty, and may have an effect of the overall value of a degree or credibility of an institution (Gallick, 1998; Johnson, Aragon, Shaik \& Palma-Rivas, 2000). This evidence provides a justification for faculty and staff to examine the online student experience to better their mastery of course material.

Traditional Classroom. According to Brandt (2006), students in a traditional classroom had a more positive perspective on the learning environment through a study that examined English and math courses at a community college. The results of the study suggest that students tended to do significantly worse in online courses when compared to traditional classrooms (Brandt, 2006). Success in traditional classrooms versus the online format is often measured in course persistence and end-of-course grades (Xu and Jaggars, 2011). Further, research conducted by O'Malley and McCraw (1999) posits that students believe they learn more in traditional classrooms and overall preferred a traditional classroom environment to online courses.

Finally, researchers have identified that the concept of "anytime, anywhere" learning in an online classroom may create some complications compared to the traditional classroom (Johnson, et al., 2000; Xu and Jaggars, 2011). The ability to log-in whenever and from any location, limits the ability of immediate constructive feedback. Research indicates that the proximity of feedback to questions and discussion in traditional classrooms has a direct and positive influence on student learning and cognitive outcomes (Brandt, 2006; Gorham, 1988). Immediate response is challenge for online instructors and students, but should be considered in course design (Richardson \& Swan, 2003). There is a presence in the traditional classroom that faculty have control over to influence learning and engage active learning and live feedback critical to a student's success (Brandt, 2006; Gorham, 1988). Overall, traditional classrooms serve as a space to verbalized information in a captive audience and discuss queries about a particular subject.

Learning Process: Online and Traditional. Several research studies suggest social presence and interaction among students and the instructor contribute to the effectiveness of an online course (Ally, 2014; Davies \& Graff, 2005; Lehamn \& Conceicao, 2014; McLaren, 2004; Swan, 2001). Specifically, Davies and Graff (2005) found that greater online interaction was not significantly associated with higher performance for students achieving passing grades; however, students who failed in their online classes tended to interact less frequently (Davies and Graff, 2005). Swan (2001) concluded, "interaction with instructors seemed to have a much larger effect on satisfaction and perceived learning than interaction with peers" (p. 322). The significance of engaging faculty to student communication and connection is essential to student success in both contexts. 
Studies indicate how crucial it is for a deeper learning experience to have interaction between fellow students and the instructor (Garrison \&Cleveland-Innes, 2005; Kop, Fournier, \& Sui Fai Mak, 2011; Lehamn, \& Conceicao, 2014). In a deeper learning approach, students search for meaning and have thought provoking answers to the material they are studying. In surface learning, students work to complete the task at hand, instead of putting in effort to understand and learn the material and work towards a grade (Garrison \& Cleveland-Innes, 2005; Smart \& Cappel, 2006). Further, numerous studies have demonstrated that a student's active involvement in the learning process enhances learning (Benek-Rivera \& Matthews, 2004; Sarason \& Banbury, 2004, Smart \& Cappel, 2006). Moreover, Ally (2014) stresses the importance of interactive learning in an online setting and to inform online learners of learning objectives to engage deeper learning. In the subsequent section, we discuss the framework of our research study in which we examine student learning in online versus traditional formats.

\section{Theoretical Framework}

This study employs a qualitative framework as we explore the learning cycles of students enrolled in the Leadership Styles and Strategies in a Diverse Society course through two methods of delivery, a) online and b) traditional classroom settings. In particular, we call on the work of David Kolb and ELT. Experiential learning is categorized as knowledge transpired into reality through transforming experiences (Kolb, 1984). ELT is related in two engaging experiences Concrete Experience (CE) and Abstract Conceptualization (AC) and two methods of transforming experiences - Reflective Observation (RO) and Active Experimentation (AE) (Kolb $\&$ Kolb, 2005). Further, Kolb (1984) also noted learning styles within the learning process, which are situated in each experience - diverging and assimilating, as well as accommodating and converging (see Figure 1) (Kolb, 1984).

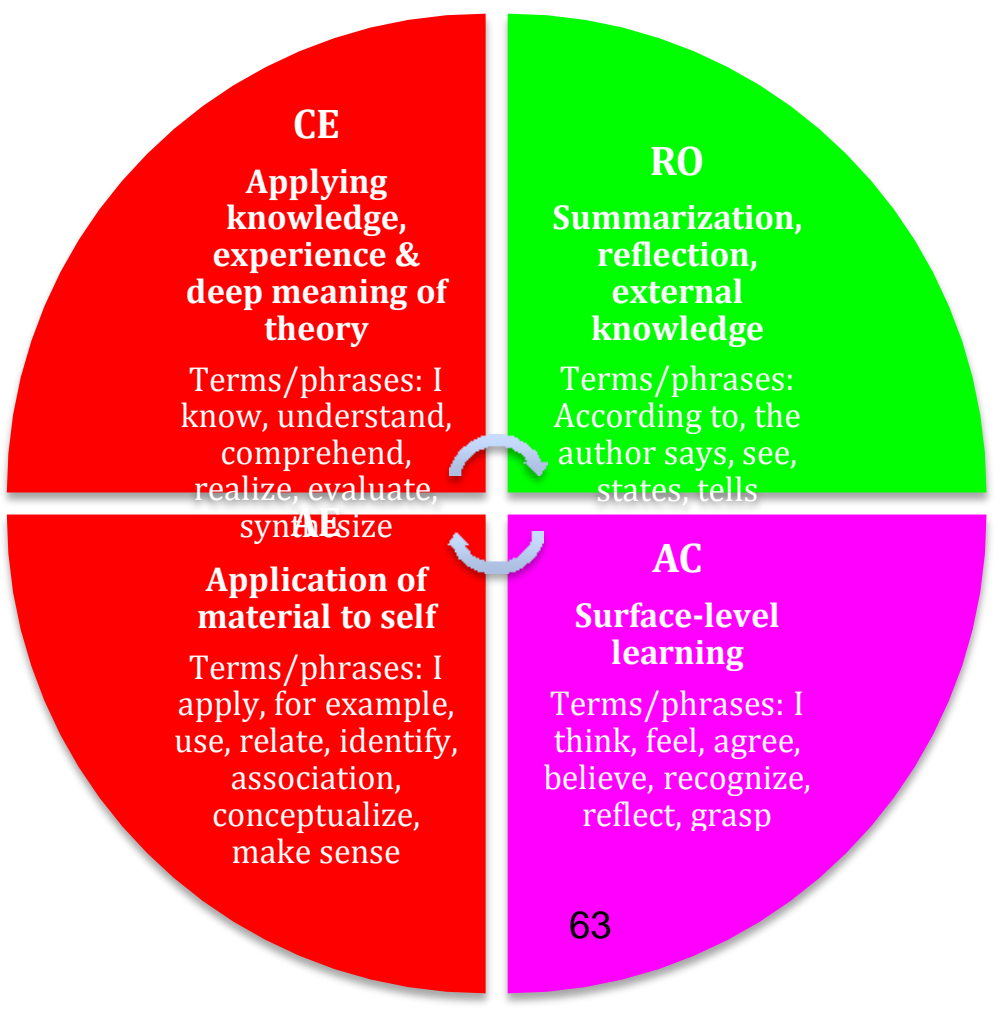


There are other experiential learning models that address the learning process through experience and application, however we argue that Kolb's ELT and the emphasis on reality, transforming, and deliberate application of experiences is the best fit for our study since our course enrolls traditional-aged college student emergent leaders. Further, since Kolb's ELT is a foundational theory, several leadership researchers have utilized ELT to support the learning process of emerging adults and leadership development (Fisher Turesky \& Gallagher, 2011; Maier, \& Thomas, (2013). ELT guides how students process and make meaning of course material and discussions. We institute this model as a framework to guide analysis of student learning from student coursework data.

\section{Methodology}

Employing a qualitative methodology allows us to examine how students reflect, process, and make meaning of their course assignments. Qualitative methods are beneficial for this study because it allows the researchers to better understand how students learn in an online and traditional classroom environment. The goal of this study is to examine the students' ELT learning process on course assignments in both online and traditional classrooms. Maxwell (2005) highlights personal goals and experiences having influence on the choice of qualitative research. In other words, our purpose is to uncover the college student learning process through how students understand course concepts in their homework. As researchers and course instructors, we have an interest in learning how students engage and make meaning of material on assignments to improve upon the course materials and design. Charmaz (2006) states "methods alone -- whatever they might be - do not generate good research or astute analysis. How researchers use methods matters" (p. 15). In other words, we posit that qualitative methods will provide an extensive portrait of student experiential learning to understand how learning environments differ.

In particular, we believe qualitative content analysis is a natural fit for examining coursework and text (Zhang \& Wildemuth, 2009). This study engages a content analysis of student data from a 300-level leadership studies course. In particular, we institute a directed content analysis approach to analyzing student coursework. "The goal of a directed approach to content analysis is to validate or extend conceptually a theoretical framework or theory. Existing theory or research can help focus the research question" (Hsieh \& Shannon, 2005, p. 1281). Further, we employ this method of inquiry during analysis as we intentionally coded documents utilizing Kolb's ELT as a conceptual framework (appendix A). Identifying a theoretical perspective prior to examining the data allows us to purposefully add to the understanding of an existing theory. This structure provides a premeditated examination of key identifiers and concepts when scanning coursework documents during data analysis (Hickey \& Kipping, 1996; Potter \& Levine-Donnerstein, 1999

This study examines coursework data from the spring 2016 semester (January 2016 to May 2016) from 30 students enrolled in the 300-level leadership studies course at a large, public, Midwestern university. Unlike previous research on online courses, this study solely examines identical courses assignments in an online and traditional course, both submitted electronically through the university course management system. Previous research also examines online courses in their entirety through student discussions posts, perceptions, and grades. We 
specifically intend to examine learning style on course assignments in both online and traditional deliveries.

Procedures. Researchers examined and coded three identical student assignments through two course delivery formats: a) online and b) traditional classrooms. The primary investigator and instructor of the course, designed assignments as reflection worksheets that elicit student meaning of the course material. The instructor of the targeted leadership course established assignments utilizing a rubric for evaluation over the course of three semesters (spring, summer, and fall 2015) prior to the targeted spring semester course. In addition, the course employs teaching assistants to grade each assignment utilizing the established rubric. Further, the instructor addressed reliability of selected course assignments by choosing previously graded coursework in which $80 \%$ of students scored $85 \%$ or higher over a span of three semesters. Students in both teaching formats completed their work in word documents and submitted through the university's course management system.

Participants. We employed a purposeful sample in which the leadership courses' teaching assistant invited 79 students ( 37 in the traditional course and 42 in the online course) to participate in the study via email (in both the online and traditional course) and through a verbal announcement in the traditional classroom during students' spring 2016 semester. Of the 79 invitations to participate, 67\% (17 from the online course and 36 from the traditional course) of students consented to participate in the study.

As noted in figure 1, of the 30 participants in the study, $80 \%$ were women and $20 \%$ were men in the online course and $47 \%$ male and $53 \%$ women in the traditional section. The course was comprised of a plethora of student classifications in both course deliveries: ten seniors, two juniors, two sophomores, one freshman in the online course and three seniors, nine juniors, two sophomores, and one freshman in the traditional section.

Data Analysis. A directed content analysis of student data enhanced the understanding of how student learning differs in the online and traditional classroom environment. Specifically, the researchers called upon the work of David Kolb and ELT to guide their content analysis of student assignments. Employing this framework assists in narrowing the coding process to view for key terms, words, or phrases that students might use to exemplify a particular mode of learning through experiential learning. Hsieh \& Shannon (2005) suggest, "the findings from a directed content analysis offer supporting and non-supporting evidence for a theory. This evidence can be presented by showing codes with exemplars and by offering descriptive evidence." (p. 1282). This study intends to provide evidence or student learning on course assignments using Kolb's ELT to better understand online and traditional course deliveries.

Prior to the coding process, the researchers met to establish a coding key, which identified the key terms, phrases, and content connected to Kolb's model analyzed in student assignments. Initially in the coding process, researchers scanned the student electronic documents for key terminology around learning and understanding such as "I applied", "This means", "I attribute", "the connection", "I learned", "reflection of theory", "I understand", "I observe", "I think", etc. (appendix A). These terms were highlighted along with any other emergent learning connected phrases. Next, the researchers coded each term with a 
predetermined code associated with experiential learning. The researchers placed the codes $\mathrm{CE}$, $\mathrm{AC}, \mathrm{RO}$, and $\mathrm{AE}$ based on the Kolb model of experiential learning with phrases that were initially highlighted (Kolb, 1984) (appendix A). The researchers initially assigned the codes to the terms and phrases the students used in their assignment documents. In addition, researchers coded whether the phrases and categories were engaged or transformative learning (Kolb, 1984).

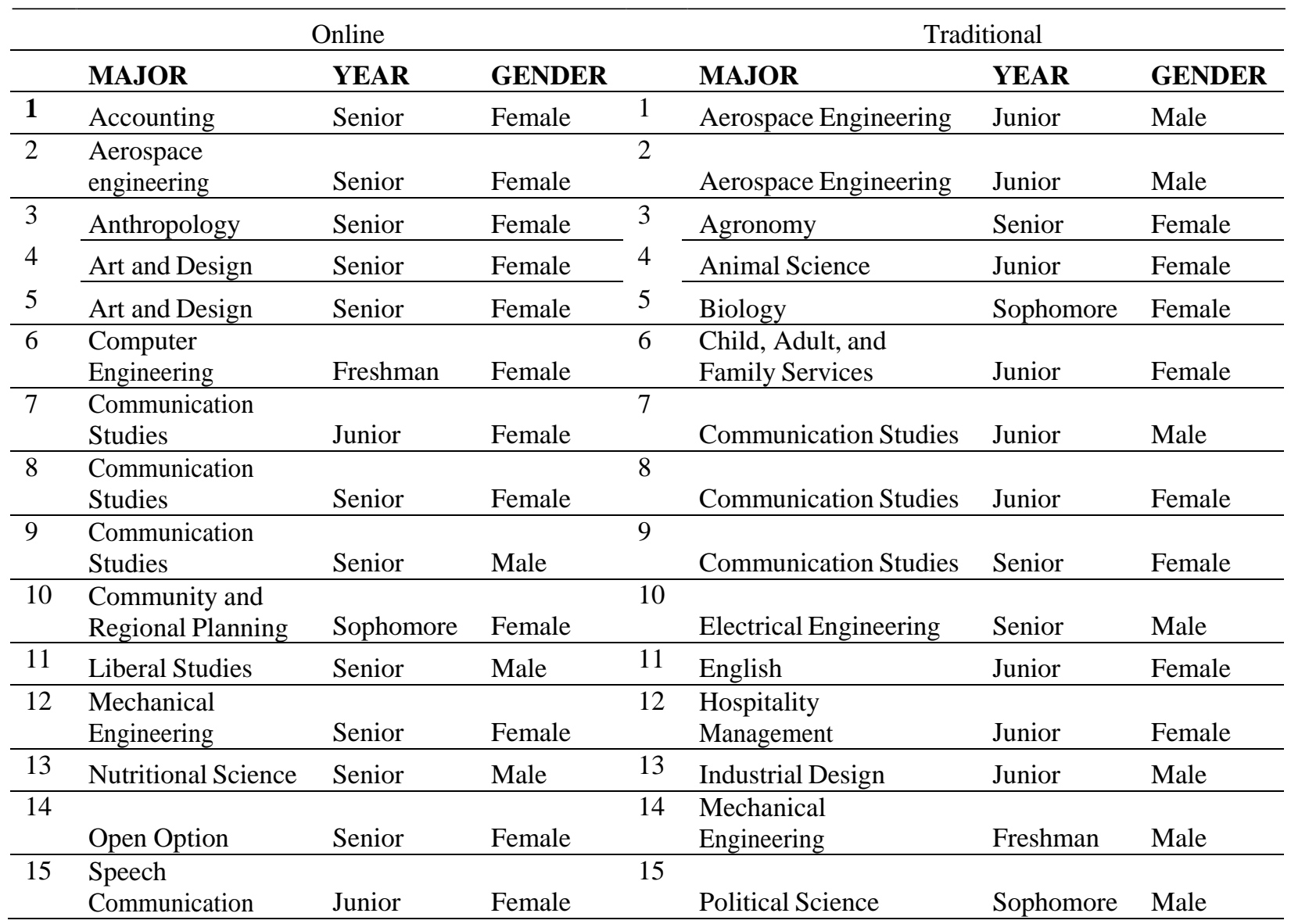

Figure 2

Further, the researchers addressed intercoder reliability through peer coding, in which the research assistant coded all electronic documents after training on association phrases and words to the Kolb model described in appendix A. The primary investigator then coded the electronic course assignment documents for consistency and to increase the trustworthiness of the findings. After two rounds of coding with the predetermined graphic on association phrases and terms (appendix A), the researchers consulted on their analysis to determine the intercoder reliability. The review process provided clarity to the level of learning in Kolb's Model. Finally, a colleague outside of the research project examined the researchers coding and findings as part of the member checking process.

Qualitative research suggests that as studies evolve, there can be cases of data saturation or examples of no new emergent themes or categories (Glaser \& Strauss, 1967; Krippendorff, 2004; Marshall, 1996). Our study reached data saturation after we coded and analyzed 12 out of 
15 student assignments in each theory category for any new phrases or words associated with Kolb's model. After reviewing the first 12 students' assignments in each category, we did not discover any new phases of content associated with Kolb's model. Overall, we analyzed and coded all 30 participants and 90 documents.

\section{Results}

Online Leadership Course Delivery. Research findings signify a predication toward particular experiential learning areas (AC and AE) for the online students (Kolb, 1984). Through analysis of student narrative course assignments in the online section of the leadership studies course, students processed their application of theory more in depth than the traditional course. Specifically, students contextualized the material through their personal leadership experiences without being prompted in assignments. For example, course assignments asked, "in your own words, how do you understand the meaning of Chaordic leadership?" To that end, students in the online section developed a response surrounding personal leadership situations that assisted in their comprehension of the approach. More than $60 \%$ of the students in the online sections went into detailed explanations of their reflections, connecting their experiences and concrete examples of how they exemplified and have enacted the theoretical perspective or leadership approach. The application and transformative examples are situated in $\mathrm{AC}$ and $\mathrm{AE}$ spectrum of Kolb's learning model and within the accommodating and converging learning style.

Findings suggest that of the online course participants, $87 \%$ of online students used an applied understanding of the course material without being promoted for their experience. The weekly course processing assignments selected to code for this study include three different sets of questions:

1. Chaordic Leadership Assignment. In your own words, identify the key three points of the chapter (Hock, 2000).

2. Strengths Based Leadership. Reflect on your own insights after reading these chapters (Rath \& Conchie, 2008).

3. 5 Practices of Exemplary Leadership. Gathering your reflections of the chapters, discuss the practice and what it means to you (Kouzes \& Posner, 2012).

Eighty-seven percent of online students used the opportunity to reflect on the main themes from each chapter or course material, however compared to the traditional course, online students provided further contextualized meaning by adding their personal experiences and connecting it to the reading and course material. This contextualization occurred without a question prompting them to share an example or a situation in which they exemplified the topics. This created a meaningful reflection and conceptualization of the topic material. One example is Byron:

I really struggle with letting these assessments shape my perspective because I find they fit me so well that I feel like I should start acting more like they say someone with these characteristics should act. I let things like StrengthsFinder occupy my thoughts for days and in every new situation I ask myself whether my strengths are shaping my actions or if my actions are what are determining my strengths. As leaders in a global society, we are 
charged with both the responsibility and privilege to use our abilities to improve our world. For us to do the most good with the skills we have a tour disposal, we first need to know what our skills are so we can organize ourselves and others into complementary positions so everyone can do what they do best. I am not the best relator or "woo" person so I need to know that when a certain circumstance requires someone with these abilities, I should not be the one to handle this type of situation. I want to enable opportunities for other people to grow and develop their own skills and build upon their strengths, which I can only do after identifying what my strengths are.

Byron is able to examine the concepts of the text through his personal experience and use the framework to process his daily skillsets. He uses analogies and how he would like to exemplify the strengths that the assessment presented to him. The synthesis is one that is thoughtful and connects concepts through an accommodating learning style.

When asked for their insights and without a question for their applied knowledge of the chapter reading, participants' in the online course provided future goals as well as insights. Further, they indicated how the theory relates to their personal experiences as a leader within secondary or postsecondary education. When compared to the traditional course assignments on Rath and Conchie's, (2008) Strengths Based leadership, $60 \%$ of online students provided a concrete situation that they would like to improve upon in the future to connect their meaning of the selected theory of leadership. For example, Tara, an online student, stated:

The biggest thing that I learned from reading these chapters is that "The most effective leaders surround themselves with the right people and then maximize their team." As I move forward throughout life, I need to do a better job surrounding myself with high achieving individuals who can push our group to become the best version we can be. If I am going to be a leader among a group like this, I need to improve my skills in team engagement so I can invest in my team members more. Ideally I would like to be able to plot the strengths of my team based on the four domains of leadership that are described in the book to hopefully have more successful teams.

Tara is able to position herself through the material and see herself as a "doer" of the approach and how this applies to future goals and reality. She uses terms like "push our group", "best version we can be", and "need to improve my skills" that create a sense of decision-making and solving problems. Her futuristic response was unsolicited yet focused on the question surrounding what the theory of strengths leadership meant to her. Tara's dialogue exemplifies Kolb's AC and AE areas of learning (appendix A).

Moreover, $73 \%$ of online students indicated reasoning and critical thought in their examples of all three theoretical approach assignments. This reasoning became prevalent when they cited several instances of participation in leadership behaviors that supported the concepts presented in their readings. One student described and attributed the same thinking in their assignment, which positions the style of convergent learning in the online setting. Michaela writes: 
I could relate to all three of these findings because I have been a leader and I have been a follower. It really comes down to the situation and how confident I am. I really agree with surrounding yourself with the right people. I tend to become friends with people who are goal driven and like to achieve success. I don't like to judge people, but you can tell right away when someone doesn't like to get stuff done and is lazy. Surrounding yourself with others who are goal oriented can inspire you to be your best and to not be lazy and to be successful. I have a lot of friends who I look up to and I am so happy to have them in my life because they push me to be the best I can be at whatever I undertake and that is very important to me.

This narrative provides a perception of how one student—Michaela, can make better decisions in her own context. She uses deeper thinking to engage how she could better her personal leadership through the approach offered in the readings for the course. She uses the terms "goal driven" "surrounding yourself", and "inspire" to shape her own decision-making. Once again, this critical thinking and process of learning connects to the convergent learning style of Kolb's ELT without being prompted to apply the theory.

Traditional Leadership Course Delivery. To the contrary, findings suggest that traditional students did not reflect in similar areas of Kolb's learning style in their assignments. When prompted to reflect on their insights on the readings, $80 \%$ of the traditional students synthesized the material, but did not critically examine their application of the approach like the online students completed. This type of learning process is congruent with AC and RO of Kolb's ELT (appendix A). One student, Meg writes:

It was very interesting to study the leader/follower relationship from the perspective of the follower. I was initially surprised that the most basic needs that a leader must meet for their followers is so personal and intimate, such as trust, compassion, and hope. However taking a step back and thinking about it, it makes perfect sense. Would I follow someone I don't trust? Or someone who doesn't treat me with compassion? How about someone who provides me with no stability or hope? The answer is no. I am so glad this book has given me a better perspective of the follower, because without followers, there is no leader. A leader is dependent on their followers.

Meg's reflection and processing of the material is describing the reflection and knowledge of the material and how she feels about it. She does not provide the action steps or plan to engage the material how she has experienced this concept, but more of her reflection on the reading and her thoughts about the concepts. Meg makes sense of the reading in her assignment through her emotions and by "watching" the information. This is a characteristic of AC because of the passivity of learning and minimal connection to experience.

Subsequently, other students exhibited this learning style on their course assignments in traditional course delivery. At least nine of the 15 students sampled reemphasized the reading material, but did not place it into their own words. Further, they added sentences stating their stance (i.e. agree or disagree) on a concept presented by the author but did not provide support for this claim. Jack provides minimal reflection on the course material: 
Another point that I found astounding is the differences in organizations who focus on their employee's strengths rather than their weaknesses. It is amazing the effects that these two perspectives have on organizations. Personally, I think it makes perfect sense that organizations who focus on strengths rather than weaknesses have more engaged and productive employees.

The minimalistic processing of the course reading creates a basic understanding of the information. Jack uses phrases such as "I think it makes sense" and "I found astounding" to connect with the information. This exemplifies RO in Kolb's ELT because it is a way to summarize the material to understand its purpose rather than placing it in contextual knowledge or application.

Further, traditional course students minimalized their learning by paraphrasing the readings rather than forming the material into their own words. This was prevalent in all course assignments examined in the study. The minimal reflection stands out because students used similar terms and language without processing the information in a way that made sense to them. Little comprehension and application clouded the student's understanding of information beyond the author's dialogue. One example is Aaron:

Hock also suggests that leadership "is about making a better person of oneself." He claims that we should spend $50 \%$ of our time managing ourselves, $25 \%$ managing our superiors, $20 \%$ managing our peers, and 5\% managing our subordinates. Viewing management as an "exercise of authority" is incorrect; rather, we should view it as a way to improve ourselves. Finally, Hock reveals his belief that "the most abundant, least expensive, most constantly abused resource in the world is human ingenuity." In other words, if we gave people the freedom and encouragement to innovate, we could accomplish great things. Giving people these opportunities is exactly what leadership is about. Leadership doesn't necessarily relate to whether a person is a superior or a subordinate.

Aaron uses the language of the author, specifically using phrases such as "Hock suggests", Hock reveals" and "he claims". His minimal reflection of the material is a reiteration of the author's information and is positioned within RO of Kolb's learning style (appendix A) because of the basic terminology and lack of independent learning or applied knowledge.

Finally, student assignments in the traditional classroom served as a space to process the author's material through reactionary complacency. Ninety percent of the traditional classroom students wrote initial reflective statements that agreed with the author's approach to leadership. There was little critical thinking framed around the concept and how the student might have critiqued the theory. Students often situated their comprehension through "liking" or agreeing with the author's points in the articles. One student writes:

Out of all of the leadership styles we have talked about so far, only McGregor's Theory $\mathrm{X}$ and $\mathrm{Y}$ talked about how the followers affected the style of leadership. I also really liked how they talked about focusing on making your strengths stronger. 
The student is able to select among theories of the semester that are prevalent in their learning style, however their reflection is lacking deep connection to the material. The student expresses that they liked the author's information without identifying a comprehension of the material outside of their reading reflection. This is categorized in the RO phase of Kolb's ELT because of its predication towards complacency with the author instead of contextualizing the information.

\section{Discussion and Conclusion}

The study indicates a difference in learning process and reflection of material in course assignments in the same class delivered in two formats. Using Kolb's ELT to understand the student data provides a context for how students may process and make meaning of the information in each setting. There are several differences to conclude in the study. This section will address what the findings mean, limitations of the study, future research, and recommendations.

This study qualitatively examines student assignments from the two different formats of the same leadership studies course. Unlike previous studies that examine the online courses in its entirety, we specifically wanted to examine course learning through assignments that were identical to the traditional class assignments and submitted through the Blackboard learning management system. Further, we did not analyze course discussions from each format or additional dialogue that may exist in-group work or in-class situations. We analyzed 3-targeted assignments using Kolb's experiential learning and highlighted findings within the study.

This study's findings support previous studies that indicate students in an online format have a greater opportunity and more time to reflect before responding (Matthews, 1999; Simonson, Smaldino, Albright, \& Zvacek, 2000). We found the difference in online and traditional classroom learning is that a deeper level of application in the online course occurred without prompting in course assignments. This is supported by the Schutte (1997) study, which indicated a $20 \%$ higher student score in the online class versus the traditional classroom. The difference in levels of deep application in the online format may be attributed to traditional classrooms offering a captive space for students and faculty to verbally reflect and discuss the subjects in detail prior to the submission of assignments. In addition, traditional classrooms provide a physical space to analyze, actively engage, and apply the student's experiences through peer-to-peer interactions and online courses may not offer a space dedicated to engage immediate peer-to-peer interactions. The access and space in a traditional classroom for verbal processing of material may serve as the vehicle for immediate student verbal reflection and serve as a catalyst for application for students. Moreover, the online environment may not provide the same captive space where students have immediacy in reflection and feedback to verbally think and process the information. Therefore, the online assignments are one of the few spaces that students can intently and deeply process the course material and do not need prompting to apply it to their personal experiences. Traditional classroom students may already verbally process and apply the information before turning in an assignment. By the time students submit work, their learning is simplified to critique only the author's work. 
The online classroom is a space where a multitude of material and information is located. Students must sift through dense information and connect learning, application, and reflection in an isolated environment. The online method of delivery allows space to synthesize material without prompts or verbal indicators from the instructor like the traditional classroom space. Online classrooms may offer this processing through video or discussion posts, yet the physical space and connection to the instructor and students is electronic and not as engaging as previous literature indicates. Our findings suggest the largest difference in learning process and application of experience to material is that online students create transformative learning without prompting. This overall theme lays a foundation of how we can adjust curriculum in the online and traditional environment and help support students in online and traditional courses. This study begins a conversation of how to evaluate and adjust course delivery methods.

Further, we posit that the traditional classroom setting can be overlooked when designing, delivering, and assessing courses. As the study indicates, faculty can be more cognizant of traditional learning on coursework assignments and how the classroom environment is designed for optimal learning. The physical classroom is a powerful space where students have verbal interaction across students and faculty. Their immediacy of reflecting and processing material is essential how they make-sense of theories and material. Faculty can assess these in-class conversations, but often do this through course assignments, which may be too late. The study solidifies that assignments in the traditional classroom should be designed based on classroom dialogue and how students connect with material to their experience. Traditional classroom assignments should deliberately ask students to connect back to course dialogue and how the student can apply the material to their realities.

Limitations and Future Research. Our study applies Kolb's ELT to one course in two delivery methods. One major limitation of the study and critique of Kolb's model is that it does not account for gendered learning styles as previous research has indicated that women learn differently than men; specifically calling on the work of Belenky, Clinchy, Goldberger, \& Tarule, (1986). The study incorporated an equal distribution of men and women in our data analysis, yet the framework did not account for gendered learning differences.

An additional significant limitation is that this study examines one leadership studies course, which enrolls students from multiple disciplines at a major research university. Given the discipline, student's ideologies and conceptual framework of learning may differ. Their reflections and applications will vary based on their discipline's overall culture, theoretical structure. Students' reflections and learning style influence their coursework and applications of material. Additionally, the study includes students from a range of ages and university classifications. The selected leadership studies course enrolls students from various levels (i.e. sophomore, junior, and senior). Given the phase of student development and educational background, student experiences and knowledge will vary based on the classification in their major and at the university.

The final limitation is faculty experience and ease with teaching in a traditional format versus the online course environment. Some faculty may have a predication toward one format or another and excel at one over another. There are several factors that influence this - years in the classroom, institutional faculty teaching support, training, funding, and faculty appointment. 
This study examines one faculty member teaching from two formats and does not assess the course evaluations and student's perceptions of the course information. Moreover, the study does not assess faculty perception of course design.

Recommendations. Instructors for online and traditional platforms should consider using explicit language in the assignments that ask students to not only reflect on course materials, but also provide specific examples of how they apply and demonstrate the information in their reality. Further, implicit learning outcomes for each module, activity, or classroom assignment help to facilitate deeper student learning. In traditional classrooms, faculty have the opportunity to guide students through deep reflection and process material through an attentive audience, peer-to-peer dialogue, and faculty interaction. This study indicates that traditional classroom assignments did not serve as a space for students to apply material to their experiences whereas the online classroom did. Moreover, traditional classroom assignments should serve as a follow up from classroom dialogue and implicitly ask students to apply their classroom discussions to the course material. The ability to create experiential learning situates itself in the learning transformation and connects the learner to knowing a reality congruent with Kolb's ELT. In addition, this affirms what previous research explains is the most significant part of online and traditional classrooms: active learning.

Furthermore, faculty should consider cognitive development and learning process of students in the online and traditional classroom setting. Moreover, faculty should encourage engagement with material over videos and passive forms of information distribution. More specifically, the online space should encompass a four-tiered approach to traditional and online learning such as this:

1. Review course information through reading material, watching videos, and lectures

2. Synthesize material through your cognitive process in assignments deliberately indicating an application of personal experience to the material

3. Apply the information through discussion, posts/videos, blogs, journals, etc.

4. Further your knowledge and synthesis of concepts to concrete experiences such as papers and projects

Finally, given the increase in online learning prevalence, higher education administration should continue to offer and train faculty on the design and delivery of online courses as well as continue faculty teaching workshops to increase the strength of teaching at the university level. A recent article by the Chronicle of Higher Education (2016) offers recommendations for preparing faculty to teach online, suggesting providing studio time and continual training on learning management systems. These programs serve as professional development and adjusting spaces of learning for the evolving student culture entering postsecondary institutions. Ongoing assessment and evaluation of courses is another method to strengthen and adjust design of faculty-taught courses.

With the growing offerings and attraction of online courses, the traditional classroom space maybe overlooked. As this study indicates, the traditional classroom delivery should be continually adapted to serve diverse student populations. One way is through teaching hybrid models or adding digital media to the traditional course. There are ways to engage immediate 
feedback and how to offer additional follow up spaces to employ constructive conversations from face-to-face course online. Specifically, offering reciprocal dialogue online in addition to the traditional course helps to expand participation for students that internally process information.

This study utilizes Kolb's ELT, which is often critiqued for not considering gender differences in learning. Genders learn and cognitively develop differently as we know from the foundational study by Belenky, et al. (1986). These differences offer better insight into adjustments and inclusivity in the learning environment. Furthermore, the study did not account for differences in student learning through disciplines. The investigated course for this study examined a multidisciplinary course with a variety of majors. Future studies should examine the different in learning process based on gender and academic discipline for college students. Moreover, disciplines and gender may dictate the assumptions and previous experiences of students that could influence online engagement and other styles of learning in the traditional classroom.

\section{References}

Ally, M. (2014). Foundations of educational theory for online learning. In Anderson, T. Elloumi, F. (Eds.), Theory and Practice of Online Learning. Athabasca, AB: Athabasca University.

Belenky, M. F., Clinchy, B. M., Goldberger, J. R., \& Tarule, J. M. (1986). Women's ways of knowing. New York: Basic Books.

Benek-Rivera, J., \& Matthews, V. E. (2004). Active learning with jeopardy: Students ask the questions. Journal of Management Education, 28, 104-118.

Brandt, D. S. (1996). Teaching the net: Innovative techniques in internet training. Paper presented at the 11th Annual Computers in Business Conference, Washington, DC.

Brown, B., \& Liedholm, C. (2002). Can web courses replace the classroom in principles of microeconomics? The American Economic Review, 92(2), 444-448.

Charmaz, K. (2006). Constructing grounded theory. London: Sage Publications.

Cole, R. A. (2000). Issues in Web-based pedagogy: A critical primer. Westport, CT: Greenwood Press.

Davies, J. \& Graff, M. (2005). Performance in e-learning: online participation and student grades. British Journal of Educational Technology, 36(4), 657-663.

Fisher Turesky, E. \& Gallagher, D. (2011). Know thyself: Coaching for leadership using Kolb's Experiential Learning Theory. The Coaching Psychologist, 7(1), 5-14. 
Gallick, S. (1998). Technology in higher education: Opportunities and threats. Unpublished Manuscript. University of California at Los Angeles, Los Angeles, CA.

Garrison, D. R., \& Cleveland-Innes, M. (2005). Facilitating cognitive presence in online learning: Interaction is not enough. The American Journal of Distance Education, 19(3), $133-148$.

Glaser, B. G., \& Strauss, A. L. (1967). The discovery of grounded theory: Strategies for qualitative research. Chicago: Aldine Pub.

Gorham, J. (1988). The relationship between verbal teacher immediacy behaviors and student learning. Communication Education, 37, 40-53.

Hickey, G., \& Kipping, C. (1996). Issues in research. A multi-stage approach to the coding of data from open-ended questions. Nurse Researcher, 4, 81-91.

Hill, P. (2016, May 24). Distance ed's second act. The Chronicle of Higher Education. Retrieved from http://chronicle.com/article/Distance-Ed-s-Second-Act/236571

Hock, D. (2000). Art of chaordic leadership. Leader to Leader, 15, 20-26.

Hsieh, H. \& Shannon, S.E. (2005). Three approaches to qualitative content analysis. Qualitative Health Research, 15(9), 1277-1288.

Janicki, T. \& Liegle, J. O. (2001). Development and evaluation of a framework for creating webbased learning modules: A pedagogical and systems approach. Journal of Asynchronous Learning Networks, 5(1), 58-84.

Johnson, S. D., Aragon, S. R., Shaik, N., Palma-Rivas, N. (2000). Comparative analysis of learner satisfaction and learning outcomes in online and face-to-face learning environments. Jl. of Interactive Learning Research, 11(1), 29-49.

Krippendorff, K. (2004). Content analysis: An introduction to its methodology (2nd ed.). Thousand Oaks, CA: Sage Publications.

Koedinger, K. R., Zhuxin Jia, J., Kim, J., McLaughlin, K. R., Bier, N. L. (2015). Learning is Not a Spectator Sport: Doing is Better than Watching for Learning from a MOOC. Proceedings of the Second. USA, 111-120. doi: 10.1145/2724660.2724681

Kolb, D. A. (1984). Experiential learning: Experience as the source of learning and development. New Jersey: Prentice-Hall.

Kolb. A. Y. \& Kolb, D. A. (2005). Learning styles and learning spaces: Enhancing experiential learning in higher education. Academy of Management Learning \& Education, 4(2),193212. 
Kop, R., Fournier, H., \& Sui Fai Mak, J. (2011). A pedagogy of abundance or a pedagogy to support human beings? Participant support on massive open online courses. The International Review of Research in Open and Distributed Learning, 12(7), 1-11.

Kouzes, J. M., \& Posner, B. Z. (2007). The leadership challenge (4th ed.). San Francisco, CA: Jossey-Bass.

Lapovsky, L. (2015, May 26). Online learning: What's next?. Forbes. Retrieved from http://www.forbes.com/sites/lucielapovsky/2015/05/26/online-learning-whatnext/\#6ed175051027

Lehamn, R. \& Conceicao, S. (2014). Motivating and Retaining Online Students: Research Based Strategies that Work. Josey Bass, San Francisco CA.

Maier, T. A., \& Thomas, N. J. (2013). Hospitality leadership course design and delivery: A biended-experiential learning model. Journal of Hospitality \& Tourism Education, 25(1),
11-21.

Marshall, M. N. (1996). Sampling for qualitative research. Family Practice, 13, 522-526.

Matthews, D. (1999). The origins of distance education and its use in the United States. T.H.E. Journal, 27(2), 54-66.

Maxwell, J. A. (2005). Qualitative research design: An interactive approach $\left(2^{\text {nd }}\right.$ ed.). Thousand Oaks, CA: Sage.

Mazzolini, M., \& Maddison, S. (2007). When to jump in: The role of the instructor in online discussion forums. Computers \& Education, 49, 193-213.

McGreal, R. (2004). Learning objects: A practical definition. Retrieved from http://www.itdl.org/Journal/Sep_04/article02.htm

McLaren, C. (2004). A comparison of student persistence and performance in online and classroom business statistics experiences. Decision Sciences, 2(1), 1-10.

Nandi, D., Hamilton, M., \& Harland, J. (2012). Evaluating the quality of interaction in asynchronous discussion forums in fully online courses. Distance Education, 33(1), 5-30.

Nash, S. S. (2005). Learning Objects, Learning object repositories, and learning theory: Preliminary best practices for online courses. Interdisciplinary Journal of Knowledge and Learning Objects, 1, 217-228.

Navarro, P. \& Shoemaker, J. (2000). Performance and perceptions of distance learners in cyberspace. American Journal of Distance Education, 14(2), 15-35. 
Nguyen, T. (2015). The effectiveness of online learning: Beyond no significant difference and future horizons. MERLOT Journal of Online Learning and Teaching, 11(2), 309-316.

O'Malley, J. \& McCraw, H. (1999). Students perceptions of distance learning. Online Journal of Distance Learning Administration, 2(4), 202-215.

Piaccino, A. G. (2002). Beyond student perceptions: issues of interaction, presence, and performance in an online course. Journal of Asynchronous Learning Networks, 6(1), 2140.

Potter, W. J., \& Levine-Donnerstein, D. (1999). Rethinking validity and reliability in content analysis. Journal of Applied Communication Research, 27, 258-284.

Rath, T., \& Conchie, B. (2008). Strengths based leadership: Great leaders, teams, and why people follow. New York: Gallup Press.

Richardson, C. \& Swan, K. (2003). Examining social presence in online courses in relation to students' perceived learning and satisfaction. Journal of Asynchronous Learning Networks, 7(1), 68-87.

Russell, T. L., (1999). The No Significant Difference Phenomenon: as reported in 355 research reports, summaries and papers. North Carolina: North Carolina State University.

Sarason, Y. \& Banbury, C. (2004). Active learning facilitated by using a game-show format or who doesn't. Journal of Management Education, 28(4), 509-518.

Schutte, J. G. (1997). "Virtual teaching in higher education: The new intellectual superhighway or just another traffic jam?". Retrieved from http://www.csun.edu/sociology/virexp.htm

Simonson, M., Smaldino, S., Albright, M., and Zvacek, S. (2000). Teaching and Learning at a Distance: Foundations of Distance Education. Upper Saddle River, NJ: Merrill.

Smart, K. L. \& Cappel, J. J. (2006). Students' perceptions of online learning: A comparative study. Journal of Information Technology Education, 5, 201-219.

Swan, K. (2001). Virtual interaction: Design factors affecting student satisfaction and perceived learning in asynchronous online courses. Distance Education, 22(2), 306-331.

Xu, D. \& Jaggars, S. S. (2013). Examining the effectiveness of online learning within a community college system: An instrumental variable approach. Retrieved from http://ccrc.tc.columbia.edu/media/k2/ attachments/examining-effectiveness-of-onlinelearning.pdf

Young, J. R. (2016, July). How to prepare professors who thought they'd never teach online. The Chronicle of Higher Education. Retrieved from http://chronicle.com/ article/How-toPrepare-ProfessorsWho/ 
Zhang, Y. \& Wildemuth, B. (2009). Thematic content analysis. In Wildemuth, B. (Ed.). Applications of social research methods to questions in informative and library science, pp. 308-319. Westport, CT: Libraries Unlimited.

\section{Appendix A}

Coding Key

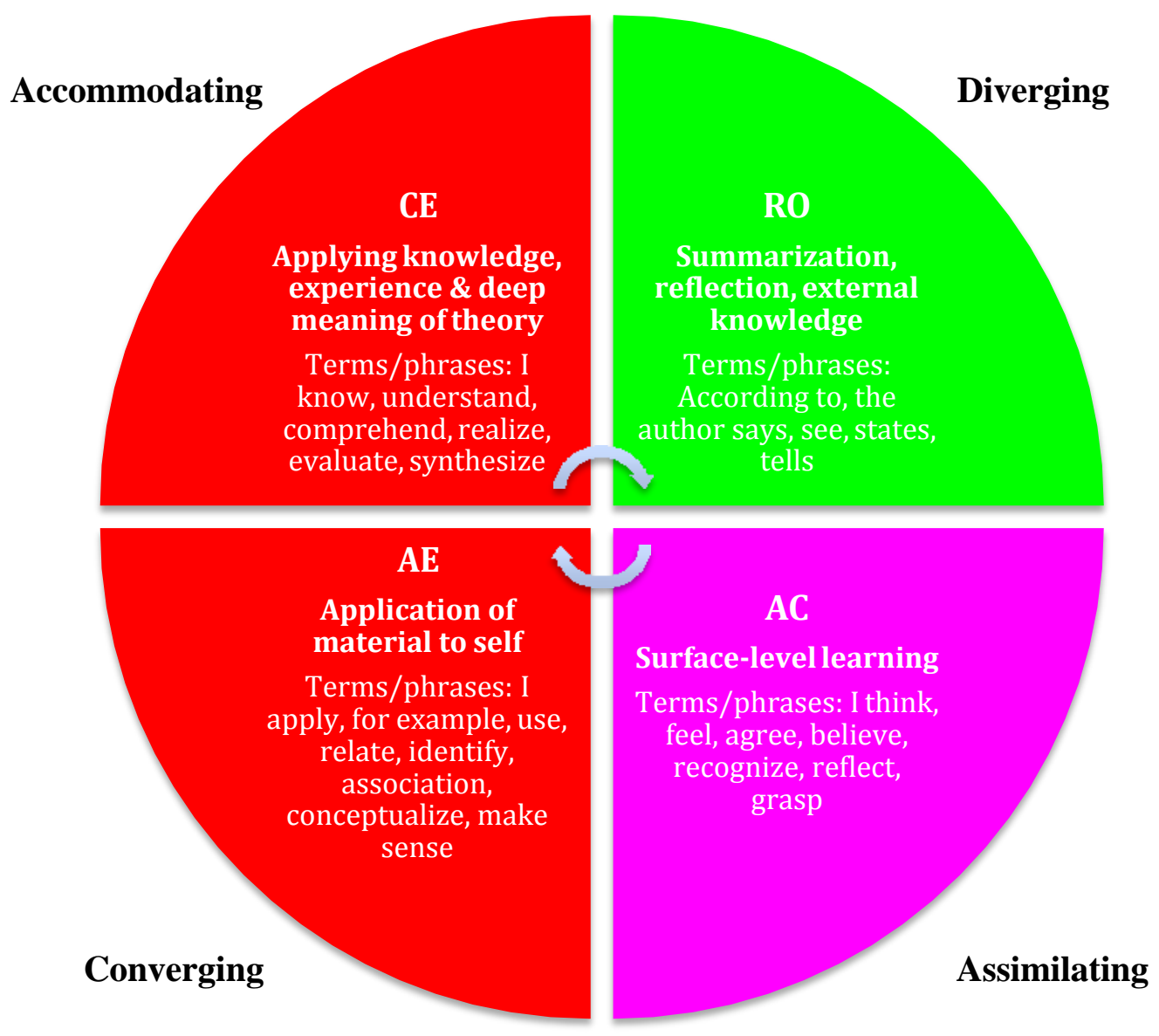




\section{Author Biographies}

Amber Manning-Ouellette, Ph.D. is a lecturer of leadership studies in the Carrie Chapman Catt Center for Women in Politics at Iowa State University. Her research areas surround women's cognitive development, women in STEM and service-learning, and college student sexuality. Her email is amouell@iastate.edu.

Katie M. Black is an undergraduate research assistant majoring in industrial engineering with a certificate in leadership studies at Iowa State University. Her email is kmblack@iastate.edu. 